\title{
DE LIEBRES, TORTUGAS Y OTROS ENGENDROS: movilidades urbanas y experiencias del espacio público en la Bogotá contemporánea
}

\author{
ÓSCAR Iván SALAZAR Arenas \\ Departamento de Sociología, Universidad Nacional de Colombia, Bogotá \\ oisalazara@unal.edu.co
}

\begin{abstract}
Resumen
Lasta hace poco, en la mayoría de trabajos sobre el espacio público había primado Tel análisis de los lugares, los peatones y la ciudadanía. Muchos de ellos habían descuidado e incluso satanizado los flujos de personas, objetos e información, así como el uso del automóvil, dentro de una concepción dual que privilegiaba el "humanismo cívico”. Esta reflexión hace parte de las recientes críticas a esas miradas y discute el concepto de experiencia urbana en su relación con una ecología urbana dinámica, móvil y transhumana. El argumento explora críticamente la metáfora de la tortuga y la liebre como herramienta interpretativa en el análisis cultural de las movilidades y su papel integrador en las prácticas cotidianas, la materialidad de la ciudad y la cultura urbana.
\end{abstract}

Palabras clave: movilidades cotidianas, espacio público, experiencia, cultura urbana.

\section{On Hares, Turtles and Other Mutants: Urban Mobilities and Public Space Experiences in Contemporary Bogotá}

\begin{abstract}
Intil recently, most studies on public space had been focused on the analysis of places, pedestrians and citizenship; in many cases those studies had neglected and even demonized flows of people, objects and information and the use of automobile, privileging a dual approach that I call "civic humanism". This reflection discusses the concept of urban experience in its relationship to a dynamic, mobile, and transhuman urban ecology. The argument explores, in a critical perspective, the metaphor of the tortoise and the hare as an interpretive tool in the cultural analysis of mobilities and its integral role in everyday practices, materiality of the city and urban culture.

KEY WORDS: everyday mobilities, public space, experience, urban culture.
\end{abstract}

Revista Colombiana de Antropología

Volumen 49 (2), julio-diciembre 2013, pp. 15-40 
De liebres, tortugas y otros engendros: movilidades urbanas y experiencias del espacio público en la Bogotá contemporánea

\section{INTRODUCCIÓN}

Fl cuento de Julio Cortázar "La autopista del sur", sobre un atasco - de tráfico en las afueras de París que dura días y quizás varios meses, podría ser leído como una distopía nacida del miedo a la inmovilidad ${ }^{1}$. El temor a un eterno trancón nos remite al sinsen-

A diferencia de la utopía, que alude a la representación ideal de una sociedad perfectamente armonizada y ordenada, las distopías, sobre todo en la literatura de ficción, han sido la imagen opuesta, la cara oculta o las consecuencias no deseadas de diseños sociales concretos, basados o no en postulados utópicos. Las distopías serían, entonces, representaciones de lo monstruoso, lo caótico y lo desordenado, y han sido utilizadas como un recurso crítico frente a distintos sistemas de organización estatal o social (Shelton 2005). tido de una inmovilidad provocada por los medios de transporte que prometían velocidad. Hoy, "la sensación contradictoria del encierro en plena selva de máquinas pensadas para correr" (Cortázar 1994, 506) es una realidad cotidiana en grandes ciudades de todo el planeta. El asunto es de tal envergadura que la inversión de recursos públicos en vías y sistemas de transporte nunca antes fue mayor, y en el caso de Bogotá nunca supuso controversias públicas tan grandes como las actuales. Pareciera que se ha operado un cambio sustancial en nuestros imaginarios: hoy nos produce menos rechazo y temor la lentitud que creemos ver en la tradición que la posible inmovilidad derivada de los riesgos percibidos o las consecuencias no deseadas de las tecnologías modernas que tanto apreciamos.

En contraste con lo anterior, entre muchos arquitectos, urbanistas y científicos sociales impera todavía un énfasis excesivo en los lugares y los emplazamientos fijos, que resulta contradictorio con el deseo de velocidad y el impulso hacia los flujos que se nos impone a diario. Lorenzo Castro (2009) plantea las relaciones entre peatones y automóviles en términos de la conocida fábula de la tortuga y la liebre, es decir, como una dicotomía excluyente entre lentitud y velocidad. Desde esta perspectiva, la fábula de la tortuga y la liebre se refiere a un deber ser frente a una realidad que estaría invertida, el cual apunta a una metáfora moralizante y simplificadora del espacio público: en las ciudades han ganado las liebres (los autos) y han perdido las tortugas (los peatones), y es malo que las liebres sean dueñas del espacio urbano y deseable que la ciudad fuese de las tortugas. Pero, en contra de los conceptos de los expertos en urbanismo y transporte urbano, a muchos ciudadanos les interesa votar por quienes los conviertan 
en liebres. Claramente, hay algo que los modelos de las ciencias sociales han pasado por alto, posiblemente porque nos hemos dedicado más a comprender y ensalzar a los peatones, las calles, los encuentros cívicos y la lentitud, y a criticar sin comprender realmente el universo de los automóviles, los sistemas masivos de transporte, las vivencias de los viajeros, la velocidad y los múltiples dispositivos asociados con la movilidad y el espacio urbano.

A partir de la metáfora de las liebres y las tortugas, en este ensayo voy a discutir el tema de las experiencias cotidianas de las personas con respecto a algunas formas de uso de las calles en ciudades como Bogotá. Situaré en el centro de la reflexión las relaciones entre peatones, automóviles y vías públicas, como elementos constituyentes del espacio público. Me concentraré en cuatro aspectos: la profundidad y la superficialidad de las experiencias, la velocidad y la lentitud de las movilidades, la imagen y la materialidad de la ciudad, y las conversiones, transformaciones y tránsitos que demandan las experiencias urbanas. Mi intención es modesta: pretendo apenas ilustrar algunas posibilidades que se abren al repensar el espacio público como un ensamblaje abierto donde resultan importantes tanto los flujos como los lugares, los agentes humanos como los no-humanos y tanto la urbs como la polis (Delgado 2007; Mongin 2006). Me interesa sobre todo resaltar la centralidad que tienen las prácticas de movilidad cotidiana en la construcción social de la experiencia y el espacio urbano. Aunque la diferencia entre urbs y polis ya había sido planteada por Henri Lefebvre, Manuel Delgado precisa bien las diferencias y relaciones de la tríada urbs, polis, ciudad. Urbs alude a las prácticas culturales, representaciones $\mathrm{y}$, en general, a la vida cotidiana de quienes habitan una ciudad; polis se refiere al ámbito de las relaciones entre los ciudadanos y el Estado y, en general, a la cultura política; la ciudad es la materialidad expresada en edificios, vías, equipamiento urbano y demás (Lefebvre, en Delgado 1999, 192-200).

La perspectiva de esta reflexión es también histórica y atiende a procesos de mediana y larga duración operados a lo largo del siglo xx, de los que hoy somos herederos. Debido a esto, varios de mis ejemplos y afirmaciones en el artículo se remiten a casos o situaciones de mediados del siglo anterior, momento en el cual las movilidades urbanas comenzaron a ser decisivas en la 
De liebres, tortugas y otros engendros: movilidades urbanas y experiencias del espacio público en la Bogotá contemporánea

configuración de las ciudades colombianas actuales. Algunos de los procesos que le dan contexto a esta reflexión son: la expansión de las redes de carreteras en todo el país a partir de la década de los cincuenta; el mejoramiento progresivo de la infraestructura urbana de vías, andenes y equipamiento del espacio público; el crecimiento de las importaciones de automóviles durante la primera década de la segunda posguerra y los inicios de la industria automotriz en el país. Adicionalmente, desde esos años las ciudades colombianas más grandes experimentaron cambios culturales y tecnológicos en cuanto a los hábitos de diversión, tiempo libre y formas de comunicación. De otra parte, las transformaciones más representativas en los sistemas de comunicación incluyen, como uno de los hitos más mentados, la introducción de la televisión en la década de los cincuenta, pero también habría que resaltar la consolidación de las cadenas de radio, la expansión de las redes de telefonía fija e, indudablemente, la aparición de la telefonía móvil a finales del siglo anterior.

En este contexto, propongo desmontar la dicotomía de las liebres y las tortugas (automóviles versus peatones) con el fin de adquirir una mirada más comprensiva de las movilidades urbanas. Mi propuesta está alineada con posturas recientes que no ven en las ciudades productos puramente humanos que eventualmente podemos controlar y dirigir a voluntad, sino ensamblajes complejos, espacialmente abiertos y atravesados por múltiples tipos de movilidades que incluyen el flujo y la interacción constante de personas, otros seres vivos, objetos e información. La imagen propuesta implica pensar la ciudad como un orden parcial y dinámico, como una ecología de objetos, materiales, ideas, personas, animales, en donde el ser humano no es el centro, no determina ni lo decide todo. Se trata de una perspectiva que algunos autores han denominado transhumana, ya que descentra la comprensión de la ciudad de la acción exclusiva de nuestra especie sobre ella e involucra todo aquello que tradicionalmente hemos visto solo como producto de nuestros actos o como objetos sin capacidad de agencia (Amin y Thrift 2002, 26-30). Aunque comenzaré por algo entendido como netamente humano, la noción de experiencia, pretendo ilustrar progresivamente la forma en que las experiencias personales están profundamente entroncadas con universos materiales y simbólicos que nos obligan a descentrarnos del humanismo extremo aún imperante en los estudios urbanos. Antes de entrar en materia, me permitiré 
una breve digresión para situar mi argumento en el campo de los estudios contemporáneos de movilidades.

\section{El uRBANISMO MÁs ALLÁ DEL HUMANISMO: PROPUESTAS DESDE LAS MOVILIDADES URBANAS}

o que recientemente se ha denominado giro móvil alude a un paradigma de investigación que privilegia el análisis de y desde las -movilidades en todos los campos y disciplinas de las ciencias sociales. Aunque existen numerosos antecedentes del uso de la movilidad como metáfora y asunto de reflexión (en la antropología pueden verse los trabajos de Augé 1994; Clifford 1997; Marcus 1995), esta mirada ha tenido un especial impulso entre algunos sociólogos y geógrafos europeos y norteamericanos en la última década. Uno de sus autores representativos ha sido el sociólogo John Urry (2000; 2008), quien concretó muchas de las bases de esta corriente al cuestionar la centralidad del concepto estático de sociedad y proponer un cambio de perspectiva epistemológica que se centraría en las movilidades y el cambio como principios orientadores de las ciencias sociales (Urry 2008, 368-503)22.

A partir del giro móvil han surgido nuevas miradas sobre el urbanismo y la comprensión de las ciudades. Dentro de este campo, Amin y Thrift señalan que

[...] mucho de la vida en la ciudad [...] está referido a la circulación de cuerpos, discursos y objetos como si fueran máquinas, así como a la presencia y regulación de vida transhumana e inorgánica (desde las ratas hasta los alcantarillados). El nuevo urbanismo debe reconocer este hecho en diversas tecnologías de regulación (tales como señales de tráfico, reglas postales, manejo de desechos). $(2002,26)^{3}$

Esta postura no implica negar el origen humano de las materialidades que componen las ciudades o deshumanizar los estudios de la

2 Puede consultarse también la revista Mobilities, publicada desde el año 2006. Para revisiones de literatura en este campo, véase Cresswell (2006, 1-24) y, especialmente, Adey (2010).

3 Traducción propia del original: "[...] much of city life $[. .$.$] is about the machine-like circulation$ of bodies, talk and objects, as well as the presence and regulation of trans-human and inorganic life (from rats to sewers). The new urbanism needs to recognize the certainty through varied technologies of regulation (such as traffic signs, postal rules, waste management)". Para una elaboración más detallada de este argumento, véase Amin y Thrift (2002, 78-104). Para otras miradas del urbanismo relacionadas con las movilidades, véanse Graham y Marvin (2001) y Ascher (2004). 
De liebres, tortugas y otros engendros: movilidades urbanas y experiencias del espacio público en la Bogotá contemporánea

ciudad. Se trata de resaltar la relativa autonomía y capacidad de agencia que adquieren esos objetos sumados al mundo por los seres humanos, en el sentido de cosas y acciones nuevas con las que hemos coproducido el entorno construido que es la ciudad.

En esta línea, Delgado está entre quienes han criticado la centralidad excesiva del humanismo en los estudios urbanos y el análisis del espacio público. Califica como "retórica ciudadanista" aquella perspectiva según la cual el espacio público debería ser entendido como ágora y como lugar fundamental para la construcción de la ciudadanía y la identidad política de la nación (2011, 15-40). De otro lado, en una investigación sobre las aceras y las prácticas sociales, Bloomley (2011, 17-29) ha llamado a esta misma postura "humanismo cívico", con similares conclusiones a las de Delgado. Aunque este no sería el sitio para abrir este debate, resulta pertinente señalar dos de los problemas del enfoque humanista: uno, la confusión que genera entre la esfera pública —como lugar de lo político, la política y los intereses comunes-y el espacio público — como sistema de lugares y espacios materiales de la ciudad-; y dos, dicho discurso incluye en un mismo paquete a todos los habitantes de una ciudad o una nación, bajo la figura de un ciudadano abstracto, generalizado y homogéneo, muy pertinente para los análisis jurídicos, pero equívoco e impreciso para describir y comprender las prácticas reales de las personas en las calles, plazas o parques. Es necesario un enfoque capaz de incorporar las experiencias concretas de las personas para pensar el espacio público sin idealizar su sentido político o cultural, aunque sin desconocer que esa es una de sus dimensiones. En este sentido, un trabajo clásico que es profundamente humanista, pero que no idealiza la ciudadanía, es el de Jan Gehl (2006), que apuesta por recuperar la escala humana en el diseño urbano, sobre el que volveré más adelante.

\section{EXPERIENCIAS PROFUNDAS Y SUPERFICIALES}

$\mathrm{n}$ tanto que aparato para organizar, separar y controlar, la modernidad requiere de la movilidad, del cambio de posi- ciones y, también, de la transformación constante de objetos, personas y experiencias. La burocracia y el Estado nacional son partes del andamiaje de conversión y movilidad constante de la 
modernidad, aunque a algunos les parezca que se están quedando atrás y se vean como lastres para los flujos. Richard Sennett (2006) se refiere a esta contradicción desde el punto de vista de los cambios en las formas de trabajo y la cultura en el nuevo capitalismo. Señala cómo la experiencia acumulada mediante años de trabajo y dedicación a una labor en el sistema burocrático tradicional hoy se ha desvalorizado a favor de las capacidades potenciales y la flexibilidad para cambiar rápidamente de tareas. La conversión que opera sobre materias primas para volverlas productos y servicios también se les aplica a los seres humanos que participan de esa maquinaria.

En contraste con Sennett, Baricco (2008) explora otra dimensión de la experiencia: aquella que valoran "los bárbaros” ${ }^{4}$ y que busca todo aquello que les da la posibilidad de moverse. Ya no hay esencias ni contenidos fundamentales, sino enlaces (links). Está en crisis la idea de que el saber implica penetrar a profundidad para comprender el fondo de las cosas. Ya no se trata de un punto, sino de una trayectoria; el saber es algo que está en la superficie de las cosas, disperso y por fuera de ellas mismas: "Superficie

4 El ensayo de Baricco utiliza el término "bárbaros" en un sentido irónico que alude a aquellas personas, comportamientos o prácticas que suelen ser considerados no refinados, no civilizados o incorrectos con respecto al discurso o las representaciones hegemónicas de una cultura. Baricco muestra lo artificioso de esas divisiones en relación con gustos, tecnologías y saberes del mundo contemporáneo. en vez de profundidad, viajes en vez de inmersiones, juego en vez de sufrimiento" (Baricco 2008, 90). Se trata de una apuesta por experiencias superficiales y veloces. Los "bárbaros" buscan experiencias que duren únicamente el tiempo necesario para lanzarse a otro lugar y no para quedarse en ellas. Los bárbaros buscan sistemas de paso, lugares donde sea fácil y rápido entrar y salir. Su meta es el movimiento en sí mismo.

Se trata, entonces, de la experiencia profunda y la experiencia superficial. La primera, como acumulación de conocimiento trascendente, y la segunda, como vivencias pasajeras; una requiere perseverancia, paciencia, estabilidad; y la otra requiere riesgo, flexibilidad y tolerancia a la ambigüedad. ¿Podríamos leer el espacio público bajo esta clave? Mi propuesta es intentarlo y, por esa vía, hacer visible lo que tradicionalmente hemos ignorado del espacio urbano en las ciencias sociales y humanas.

Cresswell señala la existencia de dos posturas aparentemente antagónicas para comprender el espacio: una, que califica de 
De liebres, tortugas y otros engendros: movilidades urbanas y experiencias del espacio público en la Bogotá contemporánea

metafísica sedentarista, que privilegia el lugar y lo que está fijo, y otra, denominada metafísica nomádica, que se centra en los flujos, los cambios y las mutaciones (Cresswell 2006, 25-51). Así, a partir de cierta metafísica sedentarista, mucha de la producción académica sigue reproduciendo la idea de que en los barrios hay fundamentalmente comunidades, acumulación y transmisión de conocimientos colectivos que se arraigan al territorio y al pasado. En contraste, en las avenidas y autopistas se han visto, ante todo, sitios de paso, ámbitos de desarraigo, infraestructuras para la velocidad, relaciones impersonales entre extraños, homogeneización y simplificación de la experiencia.

Las que aquí llamo experiencias superficiales han sido descritas y pensadas desde la sociología de Georg Simmel, pero nuestra nostalgia de lo comunitario como algo tradicional y estable tal vez haya nublado nuestra comprensión de ellas a tal punto que hoy se nos revelan como revolucionarias, cuando habían estado allí desde el comienzo de la urbanización moderna. Una relectura reciente de la idea de comunidad en el ámbito urbano la redefine no desde las relaciones cara a cara y la cercanía, como fuera para los primeros analistas de las ciudades, sino como configuración de relaciones constantemente mediadas que no necesariamente implican interacción cara a cara, y que también pueden existir distantes y dispersas en tiempo y espacio (Amin y Thrift 2002, 41-48). En buena parte de estas comunidades urbanas no tradicionales la movilidad es fundamental, a diferencia de la localización y el confinamiento que suponía la noción tradicional.

Para retomar mi asunto central, conviene aclarar a qué noción de experiencia me estoy refiriendo. Ante todo, hablo desde un punto de vista pragmático, cercano a la concepción de Dewey, en la que la experiencia cobra vida en la generación de un saber práctico y aplicado, basado en acontecimientos y saberes previos, pero ante todo proyectado hacia los actos futuros (Dewey, citado en Sáenz Obregón 2008, 163). Esta experiencia nos lleva a la acumulación de conocimientos sobre las personas y las identidades, los lugares y los ritmos de la ciudad, que se decantan en aquellos saberes prácticos que Rotenberg denomina conocimiento metropolitano (2002). Se trata de un saber adecuado para vivir en una ciudad específica, que solamente se adquiere por medio tanto de la permanencia en tiempo y espacio, como del establecimiento de relaciones sociales relativamente estables que conforman una experiencia profunda. 
Podemos pensar la importancia de las experiencias superficiales y sus relaciones con las profundas al atender a lo que ocurre a diario en la calle. De acuerdo con Gehl, el tipo de actividades que suelen tener lugar en el espacio público, adicionales a su indispensable función de circulación, son aquellas que se dan de manera voluntaria, espontánea y no planeada. En el marco de ellas se producen ante todo contactos casuales, relaciones pasajeras y de baja intensidad que pueden ser calificadas de superficiales (Gehl 2006, 23). En las ciudades occidentales los lugares para las relaciones familiares y con amigos, o para interacciones de alta intensidad, serían sitios de acceso privado o restringido en lugar del espacio público. Sin embargo, tras décadas de críticas y replanteamientos del urbanismo funcionalista, por el que apostaban los Congresos Internacionales de Arquitectura Moderna (CIAM) $^{5}$, hoy se sabe bien que el uso intensivo del espacio público para múltiples actividades, ya sean superfluas o trascendentes, brinda seguridad y calidad de vida a las personas. Es decir, las experiencias cotidianas más su5 En estos congresos se propusieron los postulados del tipo de arquitectura liderado por Le Corbusier durante años, que privilegiaba diseños urbanos despojados de ornamentos y orientados a resolver problemas prácticos de las ciudades modernas. El primero de estos congresos se realizó en 1928. Para más información puede verse Hall (1996, 216-252).

6 El término flâneur alude a un peatón o paseante que recorre las calles lentamente, sin rumbo fijo y sin intenciones de consumir o comprar, sino simplemente con deseos de disfrutar de las multitudes y distracciones de la calle.

perficiales en las calles tienen implicaciones colectivas profundas en el largo plazo y a gran escala, que también afectan a los individuos y moldean nuestro conocimiento metropolitano concreto.

\section{DE LA MUCHEDUMBRE A LOS FLUJOS, AUTOMOVILIDAD Y PEATONALISMO}

De acuerdo con la sociología urbana y las miradas más clásicas del espacio público, se podría afirmar que las experiencias profundas son de las tortugas, mientras que las superficiales son de las liebres, y que hay espacios y lugares que determinan esas experiencias. Además de los flâneurs ${ }^{6}$, inmortalizados por Benjamin (2005, 421-457), que caminaban lento entre la multitud que concurría a los pasajes de París, hay otro tipo de lentitudes mucho menos discutidas y documentadas en la literatura urbana: 
De liebres, tortugas y otros engendros: movilidades urbanas y experiencias del espacio público en la Bogotá contemporánea

las de los caminantes después del almuerzo, las de los vendedores ambulantes, las de los lustrabotas, las de una pareja en un parque. Para ellos lo importante es alargar las horas, que es a la vez recorrer un corto tramo lentamente, o permanecer en un lugar todo lo que se pueda. También hay lentitud en las movilizaciones políticas, religiosas, festivas o institucionales: desfiles militares, procesiones, carnavales, protestas, que marchan lento $\mathrm{y}$, ante todo, caminan. Todas exhiben algo, pregonan, reclaman, se despliegan y generan experiencias profundas.

Si la experiencia profunda de una ciudad demanda contacto físico, interacción cara a cara e invertir tiempo en las relaciones con el entorno urbano y su gente, la experiencia superficial es más ligera, pasajera, veloz, emocionante y también más segura. Entrar a fondo y detenerse implica exponerse, mientras que ir de pasada es una manera de aislarse y estar seguro. Pero esta práctica de pasar de largo, de solo tocar y huir, no es nada nueva. Los flujos de personas en las calles, por encima de una interacción más pausada y pautada, comenzaron a aparecer en el siglo xIx en las ciudades industriales y exigieron la creación de sistemas de transporte masivo. Esos flujos cambiaron muchas de las formas de relación de la gente en las calles de las ciudades europeas y norteamericanas más importantes en la primera mitad del siglo xx. En América Latina este proceso se inició en el mismo periodo, pero solamente en algunas de las ciudades más grandes y cosmopolitas, como Buenos Aires o São Paulo. Sin embargo, con el auge del urbanismo moderno y la expansión del uso del automóvil, a partir de mediados del siglo los flujos veloces de máquinas y personas se tomaron la mayoría de nuestras ciudades (Mongin 2006, 127-159).

En la prensa bogotana de los años cuarenta y cincuenta se repetían reclamos por la pérdida de la costumbre de encontrarse a tertuliar en la calle, sobre todo en la carrera $7 .^{\text {a }}$ debido a la introducción de los autobuses y el aumento en el tráfico de automóviles (Prieto 2005, 54-55). Este y otros lamentos se repetían al calificar el proceso de demolición y construcción de nuevas calles y edificios como "la muerte de la ciudad republicana" (González Toledo 2008, 73-79, 252-258). Parecía plantearse una lucha entre tradición y modernización, en la disputa por el uso de la calle entre peatones y automóviles. Pero las demandas por el derecho a la calle por parte de los tertuliantes progresivamente cedieron terreno a los ruegos en la prensa local para que el 
Gobierno hiciera algo para mejorar la circulación en el centro de la ciudad. Este es un ejemplo de la manera como se instituyeron la automovilidad y el peatonalismo como lugares de relación entre el Estado y la población de las ciudades. De acuerdo con Featherstone:

El término automovilidad facilita la combinación de autonomía y movilidad. En un sentido amplio podemos pensar en varias automovilidades — como formas de movimiento autónomo y autodirigido-El auto en el término automóvil se refería a un vehículo autopropulsado (un carruaje sin caballo). La autonomía no se daba a través del motor, sino por la capacidad de movimiento autogobernado, liberado de los confines de las vías férreas. (Featherstone $2004,1-2)^{7}$

De otro lado, sigo a Bloomley cuando se refiere al peatonalismo como una racionalidad que vincula al Estado con las personas por medio del estímulo, la vigilancia y el control del flujo y el movimiento constante de las personas en la calle (2011, 1-17). El foco de atención del peatonalismo son los medios para asegurar los flujos y las posibilidades de circulación de los peatones, considerados como ciudadanos genéricos y abstractos, homogeneizados en el principio de circulación.

En consonancia con estas dos lógicas, aumentar la velocidad de circulación y mantener los ritmos de los flujos se convirtió en una demanda ciudadana y un objetivo de la administración pública a lo largo del siglo xx también en las ciudades colombianas. Desde mediados del siglo pasado, se volvió decisivo hacer avenidas y autopistas, pero también disolver los tumultos y mítines en las calles y regular los flujos. Donde había trancones ${ }^{8}$ se hizo necesario abrir o reformar las vías, y donde había multitudes se comenzó a imponer el peatonalismo: gente circulando. 
De liebres, tortugas y otros engendros: movilidades urbanas y experiencias del espacio público en la Bogotá contemporánea

\section{NuEVOS HEROÍSMOS: LA VELOCIDAD COMO VALOR CULTURAL}

n las ciudades de los flujos, la velocidad no solo es una medida

- del tiempo y el espacio, sino ante todo un ideal y un valor cul-tural. De esta manera, aparecen imágenes, héroes y temporalidades veloces. La experiencia profunda es afín a la producción de novelas, historias de vida y personajes célebres; la experiencia superficial genera noticias o anécdotas, y el protagonismo (si existe) es anónimo e intrascendente. La profunda se ancla en el pasado y se decanta; la superficial es del presente, se diluye y muta más rápido. Walter Benjamin (2001, 111-134) hablaba de estos cambios cuando discutía el declinar del narrador tradicional a favor del novelista moderno, y el paso del relato colectivo y reproducido oralmente entre generaciones a la noticia efímera, individual y anclada en el presente, propia de los medios de comunicación modernos. Sin embargo, con la preeminencia de los flujos en las ciudades actuales nos encontramos frente a un nuevo giro, en una intensificación de lo que Benjamin avizoró. Nuestras ciudades ya no son narradas tanto en novelas, sino que, a lo sumo, son ciudades de relato corto; y para los más bárbaros, son ciudades de blogs, juegos de video, publicidad o tweets, donde la narrativa se disuelve y funde con la imagen, los videos y la música.

Posiblemente, el tema del héroe nos permita entender esta mutación; veamos, pues, tres momentos de nuestros heroísmos. Para los historiadores del siglo xix en América Latina la construcción del héroe fue un asunto central, así como lo fueron las narrativas de las luchas de independencia de los siglos XVIII y xix. Estos relatos construyeron héroes monolíticos, profundos y trascendentales como referentes fijos de las ideas de nación que se estaban elaborando. En el sentido de esta reflexión, José de San Martín o Antonio Nariño encarnaban relatos y ritualidades estables, símbolos de un cambio profundo en todos los ámbitos de la vida americana; es decir, sus virtudes estaban en la lentitud, incluso en su fijación y permanencia (Colmenares 2008, 83-97).

Con el cine y los medios de comunicación electrónicos, el heroísmo profundo de los protagonistas de las luchas de independencia de los países de América cedió terreno ante nuevos heroísmos superficiales, livianos y mediáticos: estrellas de cine, 
deportistas, personajes del espectáculo. Al mismo tiempo, los héroes de la movilidad mecanizada se volvieron populares: en los años cincuenta, pilotos de carreras y ciclistas cobraron un protagonismo sin precedentes en los diarios. Hoy persisten este tipo de heroísmos en Colombia con Mariana Pajón ${ }^{9}$ o Juan Pablo Montoya $^{10}$, que representan el éxito a través de la velocidad, la liviandad y la utilización de medios mecánicos de movilidad como la bicicleta BMx y el automóvil de carreras. Estos héroes

9 Ciclista colombiana de BMX que ganó medalla de oro en los Juegos Olímpicos de Londres 2012 y campeona mundial del mismo deporte en varias ocasiones.

10 Uno de los pocos colombianos que ha corrido en las competencias mundiales de Fórmula 1 . En la primera década del siglo xxl se convirtió en una celebridad del deporte nacional y sus participaciones en las carreras fueron ampliamente cubiertas por los distintos medios de comunicación en Colombia.

se convirtieron en las liebres heroicas de las tortugas anónimas. En este caso, la liebre ya no compite con la tortuga porque tiene sus propios lugares y objetos: las carreteras, las bicicletas, las pistas y los autos de carreras. Las competencias representan el extremo de la clasificación, separación y funcionalización de la velocidad hasta hacerla autorreferente: se trata de la velocidad por la velocidad. Ciclistas, patinadores o pilotos de carreras son héroes que encarnan el éxito en la velocidad. Se trata de competencias entre liebres porque las tortugas están en las calles de las ciudades congestionadas y tumultuosas presenciando a distancia el espectáculo, deseando ser liebres libres.

Sin embargo, hay un tercer tipo de heroísmo que mezcla las cartas, hace posible que las tortugas sean liebres y despersonaliza al héroe volviéndolo anónimo; se trata de los personajes de la publicidad. Una propaganda reciente de carros en Colombia, que circuló en televisión e Internet, muestra a la misma persona, primero como joven, luego como adulto con hijos pequeños y después como abuelo con sus nietos; en cada momento de la vida conduce un modelo de automóvil distinto, aunque de la misma marca, lo que reflejaría cambios en los estilos de vida vinculados al automóvil. Otra propaganda asocia la libertad, el placer y la imaginación de los juegos infantiles con carros de juguete, con la velocidad y la libertad de las carreteras soleadas en medio de paisajes verdes. En estos dos ejemplos siempre hay paisajes que el auto atraviesa y no vemos ciudades. Las paradojas se hacen evidentes: los automóviles habitan ante todo las ciudades, pero alcanzan su plenitud en las carreteras, en gran medida porque en la ciudad no se puede correr; allí las liebres tienen que ser 
De liebres, tortugas y otros engendros: movilidades urbanas y experiencias del espacio público en la Bogotá contemporánea

tortugas. Paradójicamente, en la publicidad de automóviles no hay nada más urbano que el campo. Pero hay más: el héroe ahora es cualquiera que conduzca el automóvil, que encarna la velocidad y la libertad de movimiento, la velocidad de la vida. Se trata de una máquina que promete una mutación: convertir a su dueño en liebre. Se instaura un heroísmo superficial, onírico y ligero que recorre distancias; la experiencia es más intensa cuanto más rápido recorre las superficies de las carreteras, como en los relatos publicitarios.

Pero la centralidad del automóvil en la publicidad y la economía global nos hace pensar que la experiencia superficial no se desvanece tan fácilmente; está bien arraigada en los deseos, las apariencias y las necesidades de las personas. No por superficial y ligera se trata de una experiencia intrascendente; basta salir a la calle para ver cómo la mayoría de nuestro espacio público actual ha sido construido con el automóvil y cómo las vías representan la mayor parte del espacio público de nuestras ciudades. ¿Podemos, entonces, adquirir experiencias profundas acumulando vivencias superficiales propias de los lugares diseñados para la circulación? Posiblemente para algunos es necesario: aprender a moverse y fluir requiere también de técnicas; de conocimiento acumulado; de capital social, cultural y económico.

\section{IMÁGENES DE LA MOVILIDAD Y TÉCNICAS DE CONEXIÓN}

a explosión urbana cuestionó el orden social segmentado y excluyente que heredamos del siglo XIx porque visibilizó las diferencias -culturales, hizo evidentes las desigualdades sociales y, con el avance del siglo xx, también mostró la necesidad de vincular a los que no estaban integrados al orden económico y social, ni a los beneficios y el control del Estado (García Canclini 2004, 45-82). Los sistemas de transporte público, y los usos y estéticas asociadas a ellos, son expresiones tangibles de la desigualdad social, la conexión/desconexión comunicativa y las tensiones presentes en las diferencias culturales. Estos tres asuntos — desigualdad, desconexión y diferencia- hacen parte de enfoques críticos contemporáneos de las movilidades cotidianas en las ciudades, desde los cuales se problematizan algunas de las soluciones para 
las necesidades de movilidad y transporte de pasajeros que se discuten en los medios y los debates públicos en América Latina ${ }^{11}$.

En el caso de Bogotá, nuestras soluciones han estado prácticamente restringidas, desde mitad del siglo pasado, al automóvil particular y a los autobuses de transporte público operados por particulares. El sistema tradicional de buses de transporte público incorporó estéticas populares y representaciones visuales de la ciudad que tuvieron importantes cambios al inicio del siglo XXI, con la introducción del primer sistema de buses BRT $^{12}$ en Colombia — denominado en Bogotá Transmilenio-y, algo más de una década después, del Sistema Integrado de Transporte Público (SІтP $)^{13}$. La metáfora de las liebres y las tortugas vuelve a aparecer, pero vinculada ahora a otros elementos que ponen, de un lado (el de las tortugas), al sistema tradicional de buses y busetas, y del otro (el de las liebres), a los nuevos sistemas de buses. Además de la relación entre distancia y tiempo de desplazamiento (velocidad), dentro de los asuntos centrales en los debates se cuentan la eficiencia, la seguridad, la velocidad y la comodidad de los sistemas. Este último asunto es tal vez uno de los más complejos, ya que tiene relación directa con criterios estéticos, saberes técnicos sobre mecánica o ergonomía, y prácticas de distinción y diferenciación social.

A continuación, exploraré algunas imágenes (estéticas) del

11 Como ejemplos, pueden verse Ureta (2008): Jirón, Lange y Bertrand (2010) y, para el caso colombiano, algunas de las ponencias presentadas en la mesa "Prácticas socioespaciales y movilidad", en el X Seminario Aciur de Investigación Urbana y Regional (Injaviu-Aciur 2013).

12 BRT: sigla en inglés para bus rapid transit, o autobuses de tránsito rápido. Se refiere a sistemas de transporte basados en autobuses, usualmente articulados, que utilizan calzadas, carriles y paraderos exclusivos para ellos, a diferencia de los sistemas de autobuses tradicionales, que operan integrados con el tráfico de vehículos particulares.

13 A diferencia de Transmilenio, el sITP es un sistema de buses tradicional que circula por las calles compartiendo la vía con los demás vehículos, pero bajo un modelo de administración diferente al que imperó desde mediados del siglo pasado. En el sistema anterior, las empresas operadoras de buses privados tenían rutas asignadas y competían por el recaudo del dinero en efectivo en los mismos buses. En el nuevo sistema, el recaudo de dinero y la administración de todo el sistema dependen de empresas distintas a las que realizan la operación de la flota de buses. transporte público relacionadas con las conexiones espaciales y temporales que dicho sistema hace posible, centrado en los cambios de nuestros buses en los primeros años del presente siglo. 
De liebres, tortugas y otros engendros: movilidades urbanas y experiencias del espacio público en

la Bogotá contemporánea

\section{BUSES TRADICIONALES Y SISTEMA BRT}

| Jasta finales del siglo xx moverse en una ciudad como Bogotá requería de un conocimiento local particular para entender el funcionamiento de buses, busetas y colectivos, dependiente de una lógica que podría calificarse de "narrativa". Las paletas de madera tradicionales de buses y busetas, que aún existen y están siendo redefinidas y rediseñadas en el nuevo siтp, tenían los nombres de barrios, avenidas y lugares por donde pasaban los buses, así como su destino final y un número de ruta. En este sistema, era imposible deducir la manera como una ruta se encontraba relacionada con las otras, pero sabíamos cómo usarla: dependíamos de haber pasado alguna vez por los lugares mencionados en las paletas para visualizarlos o imaginarlos, y con frecuencia apelábamos a la experiencia de otros, incluso del relato directo de los conductores, para saber qué bus tomar. Además, el sistema de transporte anterior al siтp era impredecible pero altamente flexible para los usuarios, sin horarios ni paraderos fijos y con frecuencias de circulación ajustadas de forma contingente e improvisada. En este tipo de sistema no se hacían cálculos precisos de la demanda de pasajeros, y la velocidad o la lentitud para conducir por parte del chofer dependían en gran medida de la presencia de otras rutas o buses

14 En Colombia se le denomina "guerra del centavo" a la lucha entre los conductores de buses tradicionales para recoger pasajeros a lo largo de la vía. Debido a que el sistema funciona con base en el cobro del pasaje directamente en la puerta del bus, se produce una competencia constante por recoger primero la mayor cantidad de pasajeros posibles en vías compartidas por varias rutas de buses. que competían por los pasajeros y el pago de los pasajes en la llamada "guerra del centavo"14.

Con la construcción de Transmilenio se nos impuso una forma para nosotros novedosa de entender la circulación y la ciudad misma; aparecieron nuevas imágenes y señales, inspiradas en una lógica abstracta, racional y no narrativa, que pretenden mostrar a las personas cómo usar el sistema. Dentro de los dispositivos más novedosos se encuentran los mapas de rutas y paraderos, que constituyen una nueva imagen icónica de la ciudad: un mapa totalizante para uso cotidiano, replicado cientos de veces en Internet, volantes o planos en las estaciones. Por medio de él, una imagen bidimensional de la ciudad empezó a reiterarse en los circuitos de paraderos y corredores viales. Un sistema completo de transporte se volvió visible y común por primera vez para los 
pasajeros y se ensambló con la experiencia corporal, la cinestesia $\mathrm{y}$ las narrativas de busetas, buses y colectivos que siguieron y aún siguen circulando. Un nuevo lenguaje comenzó a poblar la ciudad junto con los objetos de esta nueva ecología urbana de la movilidad representada por Transmilenio y el siтp: alimentador, troncal, sistema, articulado; e incluso se han redefinido términos de uso tradicional en el transporte público, tales como estación y paradero.

Aunque se trate de un asunto altamente técnico, la implementación de los sistemas de transporte también implica la introducción de regímenes estéticos que le dan forma e imagen a la ciudad. Entre las décadas de los cuarenta y los cincuenta los autobuses se opusieron a los tranvías, no solo como un sistema más moderno y eficiente, sino también como objetos más silenciosos, flexibles, racionales e interesantes. Curiosamente, argumentos similares se esgrimieron contra los mismos buses y busetas cuando se implementó Transmilenio, con elementos adicionales a favor del nuevo sistema, tales como su alta sofisticación técnica y la racionalización basada en el cálculo preciso de viajes, ingresos económicos y cantidad de pasajeros. En síntesis, las técnicas de conexión en la ciudad se encuentran mediadas por una combinación de criterios estéticos, infraestructuras para las movilidades, discursos y objetos que coproducen los flujos urbanos.

El trabajo de Salcedo (2003) describe algunas de las percepciones y prácticas de las personas durante los primeros años de introducción del sistema Transmilenio, cuando apenas entraba en operación la primera fase. En ese momento de transición, las diferencias con lo viejo comenzaban a demandar otras formas de percepción y representación que, sin embargo, no refundaban desde cero las maneras de moverse ni de percibir la ciudad:

Las experiencias cotidianas son las experiencias sociales más disponibles para entender que lo nuevo adquiere sentido para nosotros por su poder de mostrárnoslo como copia de lo viejo, y como copia de maneras de apegarnos a lo viejo y de resistirnos a lo nuevo. (Salcedo 2003, 53)

Lo que hay es un juego de mímesis entre lo viejo y lo nuevo en los sistemas de transporte, que hoy se hace evidente con las viejas-nuevas paletas de los buses del sitr. En ellas se combina 
De liebres, tortugas y otros engendros: movilidades urbanas y experiencias del espacio público en la Bogotá contemporánea

la superficie extensiva de un sistema de transporte que busca hacerse más visible y predecible que el anterior y la experiencia metropolitana profunda de rutas que recorren los barrios mezclándose con automóviles, motocicletas y peatones en las calles secundarias.

Las paletas y diseños de buses y busetas, con todas sus formas y colores, nos muestran estéticas populares, muchas veces barrocas, que en Transmilenio desaparecen a favor de una aparente neutralidad técnica y una estética limpia, racional y minimalista. En el transporte público actual coexisten al menos dos regímenes estéticos en franca competencia, de modo que el reparto de lo sensible, desde el primer año del presente siglo en Bogotá, está progresivamente inclinando la balanza hacia la estética técnica y racional, pero sin eliminar la anterior. Los colores y formas de las busetas, los divinos niños y las vírgenes colgantes, las paletas de colores son parte de una experiencia estética profunda. En contraste, los buses articulados, la uniformidad de las estaciones, el diseño de los mapas que representan la ciudad bajo el modelo de un circuito eléctrico, de un modo plano y simétrico (a la manera de muchos mapas de trenes y sistemas de buses en otras ciudades del mundo), buscan aligerar la experiencia, acelerar la mirada sobre el plano y liberar al pasajero para que se mueva más veloz.

\section{ENSAMBLAJES, SISTEMAS Y TRANSFERENCIAS}

a estética recargada de buses y busetas contrasta con la ausencia de decoración y limpieza visual del sistema Transmilenio -y, de cierta manera, representa obstáculos para las nuevas formas de circulación. Pero, ¿qué les ocurre a los seres humanos, en su relación con los sistemas técnicos de transporte, mientras caminan por la calle o viajan en un bus?, ¿qué ocurre cuando se detienen donde no deberían o circulan por donde debería haber permanencia? Al hablar de los heroísmos vimos cómo nuestras narrativas se mezclan con la movilidad y cuestionan la separación misma entre las experiencias profunda y superficial. Lo mismo ocurre al leer las estéticas del transporte público, y algo similar vuelve a emerger si se consideran los ritmos y las dinámicas reales de la movilidad cotidiana en el espacio público. 
Nadie es siempre liebre o siempre tortuga, ya que existen más de dos sistemas de movilidades urbanas. En las ciudades contemporáneas el asunto no se reduce a tener o no un automóvil: aunque no tengamos uno, nos vemos afectados e interpelados por su existencia, y muchos de los deseos, representaciones y prácticas relativas a nuestras modernidades pasan por el sistema de automovilidad que los hace posibles. Pero el asunto no para allí: la instauración de nuevos sistemas de movilidad o los cambios en los existentes modifican a los anteriores y nos llevan a redefinir nuestras formas cotidianas de interacción. Además de los sistemas de automovilidad y peatonalismo, existen sistemas de bicicletas, carretas, camiones, energía eléctrica, aguas y desechos, entre otros, y desde finales del siglo xx se han sumado dos nuevos y poderosos sistemas que obligan a otro proceso de adaptación y coproducción del espacio urbano: inicialmente Internet y luego la telefonía móvil (Sheller y Urry 2006; Urry 2008, 459 y ss.). En medio de este panorama, lo que hacemos a diario son trasferencias entre sistemas, conexiones con uno mientras nos desconectamos del otro. Por medio de dispositivos electrónicos como teléfonos celulares, ipods y demás podemos conectarnos simultáneamente a sistemas de movilidades análogas y digitales. Debemos entender los sistemas de movilidad de manera interdependiente y conectada, lo que implica transiciones y transferencias constantes, y supone la coexistencia y el ensamblaje de experiencias profundas y superficiales.

Respecto a la velocidad en los sistemas de movilidad contemporáneos, persiste la idea de que mientras más veloz se es, más superficie se recorre y menos profundas son las relaciones con el entorno y las personas. En este sentido, Paul Virilio (1997, 13-39) analizó los efectos de la velocidad y la cultura visual de finales del siglo xx y llegó a afirmar que la velocidad eliminaba el tiempo y el porvenir al volverlo todo un eterno presente. Olvidó Virilio las superposiciones, la coexistencia de temporalidades y espacialidades, e indudablemente exageró cuando dijo que el tiempo queda eliminado por la velocidad. En callejones sin salida similares cayeron quienes celebraban o se alarmaban por la "compresión espacio temporal” de la modernidad tardía (Harvey 2004, 288-313). Como evidencia de este error, pensemos en un teléfono celular o un reproductor de música, que implican conexiones individuales absolutamente móviles únicamente si olvidamos que la información y las ondas electromagnéticas dependen también 
De liebres, tortugas y otros engendros: movilidades urbanas y experiencias del espacio público en la Bogotá contemporánea

de la infraestructura fija que permite que los celulares sean "móviles" - tales como las antenas de transmisión, las redes de fibra óptica o el sistema eléctrico-. En un sentido similar, es posible viajar en bus, caminar o conducir con atención dispersa sobre el viaje (¿se anula el espacio recorrido?) mientras se habla con alguien o se disfruta una canción, en cuyo caso se privilegia el tiempo de interacción con la música o con otras personas, o la persistencia del ritmo de actividades lentas y profundas de la interacción cara a cara. Es, pues, posible una confluencia de tiempos, espacios y prácticas lentas y veloces.

Estamos comenzando a percatarnos de que sí hay formas de habitar los lugares diseñados para experiencias superficiales y sin fricciones, como autopistas y avenidas, y de que no todo allí es flujo, dispersión y superficie. Una observación realmente atenta y sistemática logrará, sin duda, encontrar la riqueza cultural y social de los centros comerciales, a pesar de los problemas éticos o políticos que se les puedan imputar. No podemos seguir simplificando y generalizando como simples flujos aquello que amerita ser descrito y comprendido de manera más seria y rigurosa. Por ejemplo, en los mal llamados no-lugares (Augé 1994) los aparatos electrónicos permiten establecer "contactos distantes" y cercanías digitales con los más queridos, y separar y reforzar la diferencia con los extraños. Son experiencias profundas y a la vez superficiales que no pueden tener lugar sino en esos sitios. Si bien se evita el contacto con extraños y muchas interacciones se reducen a la superficie, nuestras conexiones profundas siguen siendo posibles y, además, se imponen al viaje; tal vez es gracias a ellas que recorremos diariamente la ciudad, aunque esos viajes se nos vuelvan invisibles por obvios y redundantes.

Los viajes cotidianos por la ciudad son, la mayoría de las veces, desplazamientos de personas que constantemente cambian de posición, al pasar del transporte público al sistema peatonal de andenes, cebras y puentes peatonales; o al pasar a los automóviles o taxis. No estamos ante una anomia social, como ha sido leído por algunos nostálgicos de lo comunitario puro y tradicional. Se trata de individuos que hacen recurrentes transferencias: de peatón a pasajero, a consumidor, a padre de familia; de allí a futbolista ocasional con amigos del colegio o a miembro activo de una red social en Facebook, entre otras múltiples maneras 
de hacer comunidades distantes que no dependen de territorios fijos donde se anclen la identidad, las narrativas y la historia.

Aunque lo público ahora se ve fragmentado y la pertenencia a "comunidades virtuales" del mundo digital es algo mucho más real que la idealizada plaza pública tradicional del humanismo cívico, lo público no ha dejado de existir y su redefinición está relacionada cada vez más con diversos sistemas de movilidad. Hay quienes siguen personajes en Twitter mientras se suman a los cuerpos y objetos en movimiento en los flujos peatonales o automovilísticos; es una lógica gregaria de cuerpos, máquinas, animales, objetos e información que fluye análoga y digitalmente de manera simultánea. La lógica individualizadora de personas extrañas que no se conocen, pero comparten el transporte público y las corrientes de tráfico de automóviles en las vías, contrasta con las comunicaciones y la producción simultánea de vínculos sociales gracias a las ondas electromagnéticas, los teléfonos celulares, los links y los tweets.

Cada vez parece más adecuado pensar en seres con la capacidad de transferirse, o de convertirse temporalmente, como anfibios, en agentes de uno y otro ámbitos, para quienes la superposición de lo análogo y lo digital ya es su entorno natural. En este punto, me uno a quienes están repensando la ciudad como una ecología de objetos, animales, máquinas y vida que va mucho más allá de la agencia humana. Así, podemos ver que hacemos parte de una coproducción de la ciudad, a través de las movilidades y junto con sistemas de objetos y acciones que constantemente ponen a prueba nuestro deseo de imponer un orden urbano particular. No se trata de lo análogo desplazado por lo digital, sino de simultaneidad y coproducción: la imagen del "hombre/ mujer-celular" es frecuente en las calles del centro y en otras partes de Bogotá: se trata de personas que revenden llamadas a través de teléfonos móviles en la calle y que mantienen varios de estos atados a la cintura por medio de cadenitas. Pueden encontrase también árboles, mesas o sillas de cuyos cuerpos cuelgan hasta ocho o diez teléfonos con personas alrededor que hacen llamadas ${ }^{15}$. Lo digital no tiene sentido sin lo análogo y tampoco

15 Debo algunas de estas ideas a Olga Restrepo, con quien conversé acerca de estas prácticas como ejemplos de ensamblados sociotécnicos, a propósito de la realización del proyecto "Ensamblado en Colombia. Producción de saberes y construcción de ciudadanías". lo reemplaza; más bien, se transforman mutuamente, dentro de la lógica "bárbara" de la asimilación y la incorporación. 
De liebres, tortugas y otros engendros: movilidades urbanas y experiencias del espacio público en

la Bogotá contemporánea

\section{TRANSICIÓN FINAL}

Ce pueden señalar algunas conclusiones parciales de estas reflexiones en torno a lo que he denominado experiencias profundas y superficiales en las movilidades urbanas, que, a la vez, son también desafíos teóricos para el urbanismo y las ciencias sociales que se ocupan de la ciudad. Primero, si las movilidades urbanas son múltiples, resulta indispensable cuestionar la dicotomía de las liebres y las tortugas, ya que solo alude a dos tipos de movilidades vistas como opuestas e incompatibles, y no reconoce las relaciones y ensamblajes que se dan entre ellas. Segundo, descentrar el análisis de la vida urbana de lo puramente humano permite acceder a una complejidad que a la vez involucra lo concreto, lo tangible, las representaciones, las narrativas y los discursos, más allá de la retórica ciudadanista que tiende a desmaterializar las relaciones sociales. Tercero, en el análisis de las ciudades contemporáneas y el espacio público por parte de las ciencias sociales, resulta ya imposible eludir las movilidades como un elemento fundamental y constituyente. Cuarto y último, la velocidad se ha convertido en un valor cultural que es necesario cuestionar, pero no supone necesariamente desmaterialización, eliminación del tiempo u homogeneidad cultural. Se trata, más bien, de la expresión de experiencias superficiales y profundas que algunos pueden aprovechar mejor que otros. Para terminar, quiero ampliar este último punto y dejar apenas mencionado un concepto que puede ser fundamental para pensar las movilidades: la motilidad.

La velocidad es parte de la conexión, pero ni las diferencias culturales ni las desigualdades sociales desaparecen. En realidad, hay quienes pueden maniobrar mejor que otros y tienen más motilidad, es decir, mayor libertad y capacidad de movimiento, y son quienes mejor se conectan al mercado, el sistema global o a diferentes puntos de la ciudad y el territorio. La motilidad puede entenderse como un tipo de capital y consiste en la capacidad de un actor para moverse social o espacialmente,

[...] y puede ser definida como todas las formas de acceso que pueden obtenerse (tanto tecnológicas como sociales), las habilidades incorporadas para tomar ventaja de ese acceso y su apropiación (o lo que

16 Traducción propia del original: "Motility is the capacity of an actor to move socially and spatially [... and can be defined as all forms el actor hace con ese acceso y esas habilidades). (Canzler, Kaufmann y Kesselring 2008, 193. Énfasis en el original $)^{16}$ 
Parte de lo que determina la motilidad es la libertad para optar por uno u otro medio de transporte o comunicación y, en el caso que me ocupa, la posibilidad de conectarse y desconectarse voluntariamente de los flujos del espacio público. Cuando alguien no tiene tiempo para detenerse, solamente puede usar un medio de transporte o no dispone de tiempo al aire para llamar por celular, entonces tiene baja motilidad y podría quedar desconectado del sistema de comunicaciones o, incluso, espacialmente aislado. Posiblemente no pueda tener experiencias profundas y superficiales simultáneamente, sino que deba optar por una u otra, o por alternarlas: quienes no disponen de motilidad en la comunicación se ven obligados a detenerse en la calle ante un hombre-celular para poder llamar, en lugar de seguir en el flujo urbano mientras hablan por teléfono. El que no tiene motilidad en los sistemas de transporte - por ejemplo, quien no posee un automóvil—, depende de los sistemas de transporte público o de sus propias piernas (de allí la importancia política de que existan sistemas de transporte público dignos, adecuados y accesibles).

La velocidad y la lentitud, la movilidad y el arraigo, y las experiencias profundas o superficiales no pueden ser vistas como polos opuestos. Se trata de tensiones que si bien dependen de condicionantes estructurales (conexión, diferencia, desigualdad), a la vez obedecen a interacciones, apropiaciones y mediaciones cotidianas de la gente en la calle, ya sean "ciudadanos de a pie" o "ciudadanos de automóvil"17.

En cuanto al espacio urbano, no se trata únicamente de pensar cómo hacer para que las liebres no maten a las tortugas, y si hay que mantenerlas separadas. No podemos ver como entes independientes al automóvil y al conductor, o al pasajero de bus, la máquina que lo transporta y el sistema del cual hacen parte. Ellos configuran un ensamblaje que puede ser desensamblado y reensamblado de nuevo según las prácticas, ritmos y rutinas de la vida urbana. En este sentido, hay que enfatizar el descentramiento de los análisis del espacio público de la consciencia, la acción racional, la planeación y la primacía del ser humano; debemos repensarnos como parte de un

- of access obtainable (both technologically and sociallyl, the skills possessed to take advantage of this access and these skills, and their appropriation lor what the actor does with this access and these skills)". También pueden verse los trabajos de Kellerman (2011) y Adey (2010). 17 "Ciudadano de a pie" se refiere, en el contexto colombiano, a la gente del común. Su contraste con el "ciudadano de automóvil" alude a las diferencias sociales implícitas en los sistemas de movilidad cotidiana. 
De liebres, tortugas y otros engendros: movilidades urbanas y experiencias del espacio público en la Bogotá contemporánea

ambiente construido, que no es un sistema cerrado y que se encuentra también habitado por información, máquinas, animales y objetos que trascienden la voluntad humana de ordenarlo y controlarlo. El análisis cultural de las movilidades y las múltiples experiencias y saberes que las atraviesan se ha comenzado a revelar como clave importante dentro de este propósito.

\section{ReFEREnCias}

Adey, Peter. 2010. Mobility. Nueva York: Routledge.

Amin, Ash y Nigel Thrift. 2002. Cities. Reimagining the Urban. Londres; Malden: Polity.

Ascher, Françoise. 2004. Los nuevos principios del urbanismo. Madrid: Alianza.

Augé, Marc. 1994. Los "no lugares". Espacios del anonimato. Una antropología de la sobremodernidad. Barcelona: Gedisa.

Baricco, Alessandro. 2008. Los bárbaros. Ensayo sobre la mutación. Barcelona: Anagrama.

Benjamin, Walter. 2001. “El narrador”. En Para una crítica de la violencia y otros ensayos. Iluminaciones IV, 111-134. Madrid: Taurus.

—. 2005. "El flâneur". En El libro de los pasajes, 421-457. Madrid: Akal.

Bloomley, Nicholas. 2011. Rights of Passage: Sidewalks and the Regulation of Public Flow. Londres; Nueva York: Routledge.

Canzler, Weert, Vincent Kaufmann y Sven Kesselring. 2008. Tracing Mobilities. Towards a Cosmopolitan Perspective. Hampshire; Burlington: Ashgate.

CAstro, LoREnzo. 2009. "La calle de las liebres y la calle de las tortugas". En iLa calle es nuestra,... de todos! Bogotá. Ciudad en movimiento, editado por César Guzmán, Tania Maya, Samira Kadamani y Carmen Gil, 162-169. Bogotá: Universidad de los Andes.

ClifFORD, JAMEs. 1997. Routes. Travel and Translation in the Late Twentieth Century. Cambridge; Londres: Harvard University Press.

Colmenares, Germán. 2008. Las convenciones contra la cultura. Ensayos sobre historiografía hispanoamericana del siglo XIX. Bogotá: La Carreta.

Cortázar, Julio. 1994. "La autopista del sur". En Cuentos completos 1, 505-523. Madrid: Alfaguara. 
Cresswell, Tim. 2006. On the Move. Mobility in the Modern Western World. Nueva York; Londres: Routledge.

Delgado, Manuel. 1999. El animal público. Hacia una antropología de los espacios urbanos. Barcelona: Anagrama. . 2007. Sociedades movedizas. Pasos hacia una antropología de las calles. Barcelona: Anagrama. . 2011. El espacio público como ideología. Madrid: Catarata.

Featherstone, Mike. 2004. "Automobilities: An Introduction”. Theory, Culture \& Society 21 (4/5): 1-24.

García Canclini, Néstor. 2004. Diferentes, desiguales y desconectados. Mapas de la interculturalidad. Barcelona: Gedisa.

GeHL, Jan. 2006. La humanización del espacio urbano: la vida social entre los edificios. Barcelona: Reverté.

GonzÁlez Toledo, Felipe. 2008. Crónicas bogotanas. Bogotá: Planeta; Alcaldía Mayor de Bogotá.

Graham, Stephen y Simon Marvin. 2001. Splintering Urbanism: Network Infrastructures, Technological Mobilities and the Urban Condition. Londres; Nueva York: Routledge.

Hall, Peter. 1996. Ciudades del mañana. Historia del urbanismo del siglo XX. Barcelona: Ediciones del Serbal.

Harvey, David. 2004. La condición de la posmodernidad. Investigación sobre los orígenes del cambio cultural. Buenos Aires: Amorrortu.

INJAviu-Aciur. 2013. Separata: X Seminario Investigación Urbana y Regional. Cuadernos de Vivienda y Urbanismo. Consultado en http://revistas.javeriana.edu.co/index.php/cvyu/issue/view/445

Jirón, Paola, Carlos Lange y María Bertrand. 2010. "Exclusión y desigualdad social: retrato desde la movilidad cotidiana”. Revista Invi 25 (68): 15-57.

Kellerman, Aharon. 2011. Personal Mobilities. Londres; Nueva York: Routledge.

Marcus, George. 1995. "Ethnography in/of the World System: The Emergence of Multi-Sited Ethnography”. Annual Review of Anthropology 24: 95-117.

Mongin, Olivier. 2006. La condición urbana. La ciudad a la hora de la mundialización. Buenos Aires: Paidós.

PRIETO, LeOPOLDO. 2005. "La aventura de una vida sin control. Bogotá, movilidad y vida urbana, 1939-1953”. Trabajo de grado, Departamento de Sociología, Universidad Nacional de Colombia, Bogotá. 
De liebres, tortugas y otros engendros: movilidades urbanas y experiencias del espacio público en la Bogotá contemporánea

Rotenberg, Robert. 2002. “The Metropolis and Everyday Life”. En Urban Life. Readings in the Anthropology of the City, editado por George Gmelch y Walter Zenner, 93-105. Long Grove: Waveland.

SÁEnz Obregón, Javier. 2008. “La filosofía como pedagogía”. En Filosofía de la educación, editado por Guillermo Hoyos Vásquez, 157-177. Madrid: Trotta.

Salcedo, María Teresa. 2003. "Fisonomías de lo público y lo privado en Bogotá: identidad y percepción en espacios urbanos”. Revista Colombiana de Antropología 39: 41-70.

SENNETt, Richard. 2006. La cultura del nuevo capitalismo. Barcelona: Anagrama.

Sheller, Mimi y John Urry. 2006. "Mobile Cities, Urban Mobilities”. En Mobile Technologies of the City, editado por Mimi Sheller y John Urry, 1-17. Londres; Nueva York: Routledge.

Shelton, Robert. 2005. "Utopia and Dystopia”. En Encyclopedia of Science, Technology, and Ethics, vol. 4, editado por Carl Mitcham, 2010-2013. Detroit: Macmillan Reference USA.

Ureta, Sebastián. 2008. “To Move or not to Move? Social Exclusion, Accessibility and Daily Mobility among the Low-income Population in Santiago, Chile”. Mobilities 3 (2): 269-289.

URry, John. 2000. Sociology beyond Societies. Mobilities for the Twentyfirst Century. Londres; Nueva York: Routledge.

. 2008. "Moving on the Mobility Turn". En Tracing Mobilities. Towards a Cosmopolitan Perspective, editado por Weert Canzler, Vincent Kaufmann y Sven Kesselring, 363-618. Hampshire; Burlington: Ashgate.

Virilio, Paul. 1997. Cibermundo. La política de lo peor. Madrid: Cátedra. 